\title{
Mauveína, a cor que mudou o mundo!...
}

\author{
A. M. A MORIM DA COSTA*
}

Ao tentar preparar o agente anti-malária, quinina, por oxidação da anilina obtida a partir do carvão, William H. Perkin, então apenas com 18 anos, descobriu, em 1856, um corante púrpura que chamou primeiramente "mauve" e, mais tarde, "mauveine", por referência à cor da flor da malva silvestre. Neste trabalho, apresen- tamos essa descoberta, referindo o carácter serendípico de certas descobertas científicas e também as principais tentativas que têm sido feitas para caracterizar a estrutura do corante em questão, posto ter a mesma sido objecto de interpretações diferentes ao longo de mais de cem anos.

\section{Um caso típico de serendipidade}

Perfazem neste ano de 2007, cento e cinquenta anos sobre a instalação, em Greenford, na parte Oeste de Londres, nas margens do Grand Union Canal, por William Henry Perkin (1838-1907), da primeira fábrica para a produção do primeiro corante preparado artificialmente, a mauveína. Fora o próprio Perkin quem o descobrira no ano anterior. Nas férias da Páscoa de 1856, em casa de seus pais, na parte oriental de Londres, onde dispunha de um pequeno laboratório químico que ele próprio montara, então com 18 anos, tentou sintetizar a quinina a partir da toluidina. No vasto Império Britânico de então, a malária era um flagelo em muitas e muitas partes, particularmente nas regiões ultramarinas. O conhecimento empírico do poder febrífugo das infusões preparadas com cascas de várias quinas, as assim chamadas cinchonas, originariamente descobertas no Peru, e, depois, em vários outros países da América do Sul, era largamente utilizado no tratamento desse flagelo. Conseguira-se transplantar com êxito algumas dessas quinas para outras regiões tropicais. Nos anos vinte de mil e oitocentos, Pelletier e Caventou haviam

"Departamento de Química - Universidade de Coimbra 3004-535 Coimbra - Portugal acosta@ci.uc.pt conseguido isolar o princípio activo dessas infusões, responsável pela acção curativa da malária, os alcalóides cinchonina e quinina, sendo este último o mais activo $[1,2]$.

Conhecida a fórmula empírica da quinina, $\mathrm{C}_{20} \mathrm{H}_{24} \mathrm{~N}_{2} \mathrm{O}_{2}$, de imediato os químicos orgânicos se propuseram tentar a sua síntese. Foi August Wilhelm Hofmann (1818-1892), então Presidente do Departamento de Química do Imperial College de Londres, quem sugeriu a W. H. Perkin, seu assistente desde 1853, a possibilidade de a preparar a partir de um derivado amino adequado. Perkin propôs-se fazê-lo tentando a dimerização oxidativa da alil-toluidina, $\mathrm{C}_{10} \mathrm{H}_{12} \mathrm{~N}$, com dicromato de potássio. Para surpresa sua, obteve um precipitado acastanhado e sujo que estava longe de ser a quinina que esperava. Sem desistir, tentou a oxidação pelo mesmo dicromato de potássio de um sulfato de anilina. O produto obtido continuava a não ter quaisquer semelhanças com a desejada quinina. Em vez de um precipitado acastanhado, tinha agora à sua frente uma massa escura, também ela de aspecto nada agradável. Sem se dar por vencido, resolveu purificar esta massa escura tratando-a com etanol. Fazendo-o, obteve uma bela solução com uma cor púrpura muito intensa. Não era de todo a quinina que procurava; mas era uma solução que permitia tingir a seda, conferindo-Ihe uma cor muito alegre, luzidia e brilhante, num processo simples e rápido.

De imediato, Perkin deu notícia desta sua preparação à Pullars of Perth, uma empresa que se dedicava ao fabrico e comercialização de corantes. Esta, prontamente se manteve em contacto com Perkin, encorajando-o a prosseguir com um estudo mais aprofundado sobre o composto que preparara, caracterizando melhor a sua natureza e as melhores condições de rentabilidade da sua preparação e aplicações.

À data, como ainda hoje, os tecidos de cor púrpura eram muito procurados. Os corantes mais usados para os preparar eram obtidos a partir de diversas substâncias orgânicas de origem natural, extraídas, sobretudo, de algumas espécies de murexidas ou de algumas espécies de líquens, cada vez mais raras e, consequentemente, mais caras. Não admira pois que a descoberta de Perkin se revestisse de grande valor comercial. O composto que Perkin acabara de preparar era o primeiro corante artificial que se viria a revelar de importância capital para a indústria têxtil. Perkin foi o primeiro a acreditar no seu valor. Logo em 1856, registou em seu nome a patente do novo corante de anilina que preparara quando se propusera sinteti- 
zar a quinina. Em colaboração com seu pai e seu irmão, de imediato se lançou na construção de uma fábrica para manufacturar em grande escala o mesmo corante que seria comercializado, a partir de finais de 1858, com o nome de púrpura Tiriana, por referência à antiga púrpura que em Tiro teve o seu grande centro de comercialização, um derivado bromado do índigo, a púrpura que os romanos obtinham dum molusco do mar Mediterrâneo. Todavia, no mundo do vestuário, em Inglaterra, a cor dos tecidos obtida com esse corante passou a ser comummente designada, primeiro, por "mauve", a cor da flor de malva, e, depois, por "mauveine". A Rainha Vitória, na corte Inglesa, sempre manifestou especial predilecção por esta cor. Por mais que uma vez, se apresentou em público vestindo de seda púrpura preparada com a mauveína, como foi o caso do manto que usou na abertura solene da Exposição Real de 1862. Também na corte Francesa, a Imperatriz Eugénia manifestou predilecção semelhante por essa mesma cor que considerava condizer muito bem com a cor de seus olhos.

Não tardou que a Fábrica que Perkin construira para manufacturar o corante da púrpura Tiriana começasse a preparar por síntese outros corantes do mesmo género, cobrindo um vasto espectro de outras cores, nomeadamente a anilina vermelha, a fuchsina, a magenta, a alizarina, etc... Foi apenas o princípio da grande indústria dos corantes preparados por síntese orgânica que nos anos seguintes avassalaria o mundo industrial, com grande preponderância, em particular, na indústria química da Inglaterra e da Alemanha. A pequena fábrica construída para preparar a mauveína tornou-se em poucos anos um gigante no fabrico e comercialização de corantes, e fez do seu proprietário senhor de uma grande fortuna. Depois da mauveína, Perkin descobriu e intensificou a produção de outros corantes, nomeadamente aqueles que ficaram registados como o Violeta Britannia, o Verde de Perkin e a mencionada Alizarina. Nos finais da década de 1860, a cor púrpura da mauveína foi perdendo aquele fascínio que provocara inicialmente. Mas Perkin, nos seus labora- tórios, mesmo depois de aposentado e até à sua morte, continuou a dedicar sempre um especial interesse ao seu estudo e desenvolvimento, por ter sido o primeiro corante com que iniciara a actividade industrial. A marca que deixou no desenvolvimento da indústria dos corantes justifica que ao fazer a história do acontecimento, S. Simon Garfield se Ihe refira como "a cor que mudou o mundo" [3]. A sua verdadeira estrutura química foi considerada durante anos como "o mistério da mauveína" [4]. Foram precisos cento e muitos anos para ser dado como desvendado, como mais abaixo mostraremos.

O pouco que aqui deixamos referido sobre o modo como Perkin descobriu a mauveína é o suficiente para podermos dizer que se trata dum processo típico de serendipidade. Encontrámo-la considerada como tal em vários catálogos de "Descobertas Fortuitas". Na pequena lista de "33 Casos de Acaso em Ciência" que o Professor Victor Gil seleccionou do elenco de exemplos de descobertas científicas em que o acaso desempenhou um papel importante, apresentados por alunos de várias escolas básicas de Portugal e Espanha na Semana Europeia da Cultura Científica e Tecnológica realizada em Coimbra, em 1995, sob o tema «O Acaso em Ciência», lá está, com o número treze, o caso da mauveína [5].

São muitas as descobertas científicas feitas por acaso. Nem todas são, porém, do mesmo tipo. De facto, com Jean Jacques, Professor do Collège de França em Paris, impõe-se reconhecer que no tocante à investigação e à descoberta, aquilo a que se chama acaso é necessariamente multiforme [6]. Há descobertas científicas feitas por acaso em que o grande factor é a intuição do próprio investigador; e há as que são puro e feliz acaso que surge inesperadamente quando se procura outra coisa [7]. Quando se fala de serendipidade é a estas últimas que nos referimos, utilizando a nomenclatura cunhada por Sir Horace Walpole, $3 .^{\circ}$ Conde de Orford (1717-1797), numa carta dirigida ao seu amigo Horace Mann, com data de 28 de Janeiro de 1754, referindo-se às descobertas feitas pelos Três Prínci- pes de Serendip, o paradisíaco Reino de Ceilão, hoje Sri Lanka: "enquanto viajavam através do seu país à descoberta de suas belezas, suas altezas estavam sempre a fazer descobertas, por acidente e sagacidade, de coisas que não estavam na mira da sua procura. Atentos e mentalmente bem preparados para prestar toda a atenção aos mais pequenos pormenores do que se Ihes deparava observar, deles tiravam conclusões perspicazes que a outros passariam desapercebidas e que constituíam verdadeiras e surpreendentes descobertas" [8]. É na categoria destas últimas que a descoberta da mauveína tem inteiro cabimento.

Palavra nova, o termo serendipidade não entrou ainda na maioria dos dicionários portugueses. Aparece sim no Dicionário Consultivo Luso-Brasileiro de Houaiss de 2001, acompanhado pelas variantes serendipista e serendipitoso. Todavia, o seu uso está cada vez mais consagrado, no nosso dia-a-dia, não só no domínio da história e filosofia das ciências, como até no domínio estritamente científico. Curiosamente, em 2002, foi apresentada, no Departamento de Engenharia Informática da Universidade de Coimbra, uma Tese de Mestrado intitulada "Serendipidade e Sistemas de Informação" [9]. Curioso também é referir o Projecto de Investigação em que está envolvido o Grupo científico onde essa Tese foi apresentada com publicações de impacto internacional com títulos tão sugestivos quanto o são, entre outros, "The serendipity equations" [10] ou "Programming for Serendipity" [11], ou ainda, "Searching the unsearchable: inducing serendipitous insights" [12].

Não deixa de ser, todavia, sintomático que um filme de Peter Chelsom produzido nos Estados Unidos em 2001, cujo título no original é precisamente "Serendipity" seja apresentado entre nós com o título "Feliz Acaso". Os responsáveis pela sua tradução não ousaram utilizar o termo "serendipidade". Na Internet, a frequência do termo em inglês, já ultrapassou de longe o meio milhão de vezes; na sua versão em português anda ainda pelas duas centenas. Mesmo assim, num pequeno artigo intitulado "Línguas" no jornal Globo (5 Nov. 
2001), Luís Fernando Veríssimo considerou tratar-se de um dos mais belos termos da língua portuguesa.

\section{A estrutura molecular da mauveína}

Não foi fácil determinar a estrutura molecular da mauveína. Descoberta em 1856 e com patente registada nesse mesmo ano, a estrutura química só viria a ser apresentada de modo satisfatório em 1994. Por uma razão ou outra, as explicações avançadas até então nunca se apresentaram como inteiramente convincentes.

Nos seus trabalhos de investigação sobre o corante que preparara e começara a comercializar com o nome de púrpura Tiriana, Perkin considerou que se não tratava de um composto puro, mas duma mistura de corantes. Em 1896, quarenta anos passados sobre a descoberta do corante em referência, anos durante os quais se tinham produzido e comercializado já muitas centenas de milhares de toneladas do mesmo, na sua conferência Hofmann, o próprio Perkin referia ainda que a mauveína era uma mistura duma substância que designava por pseudomauveína e um derivado trimetilado obtido a partir da $p$-toluidina tratada com anilina [13]. Em 1893 e 1896, trabalhando separadamente, Fischer [14] e Nietzki [15] mostraram que o produto obtido por oxidação da anilina pura, a pseudomauveína de Perkin, era um sal de $\mathrm{N}$-fenilfenazina. De acordo com estes estudos, a mauveína de Perkin seria uma mistura de dois compostos que diferiam entre si por um grupo metilo que passaram a designar por mauveína-A e mauveína-B, cujas diferenças estruturais passaram a ser objecto de almejada caracterização. Todavia, o acordo entre os seus estudiosos não tem sido fácil.

O primeiro catálogo de substâncias utilizadas como corantes, publicado na Alemanha em 1888 por Gustavo Schultz e Paul Julius [16] na comemoração dos setenta anos de Hofmann, referindo a mauveína indicava apenas a sua fórmula empírica; porém, na sua terceira edição, em 1897, tomando em consideração os referidos trabalhos de Fischer e Nietzki, ao referir-se ao composto indicava que a sua estrutura molecular era pura e simplesmente a componente daquela mistura considerada como mauveína-B. Esta estrutura passou a ser aceite sem grandes reticências por outros catálogos. Mas a questão não estava de todo clarificada.

Em 1906, para marcar os cinquenta anos da descoberta do corante, a Sociedade Americana de Química ofereceu a Perkin um serviço de chá, em prata, onde estavam gravadas referências a várias das mais significativas contribuições do autor para o progresso da química. A referência à descoberta da mauveína estava assinalada com a estrutura da pseudomauveína, a mauveína-A. Mas, em 1924, o "Indice de Cores" editado pela Sociedade de Corantes e Coloristas [17] voltava a insistir na estrutura molecular da mauveína-B. Fixando-se nesta, em 1925, o austríaco Cobenzl, um perito em corantes, relatava alguns trabaIhos em que mostrava que o mosto de várias arilaminas era das melhores matérias a utilizar com maior rendimento na síntese da mauveína pelo facto da estrutura molecular desta incorporar duas moléculas de o-toluidina, uma de $m$-toluidina, uma de $p$-toluidina e uma de anilina, resultando na estrutura molecular da mauveína-B [18] de acordo com o esquema abaixo.

Esta relação da estrutura molecular da mauveína com as moléculas dos três isómeros da toluidina e com a molécula da anilina lançou nova luz sobre a preparação da mauveína por Perkin usando toluidina. A alil-toluidina que terá usado terá sido um desses muitos compostos tornados disponíveis, nas primeiras décadas do século dezanove, pela indústria do alcatrão preparado a partir do carvão. A ser assim, estaria longe de ser alil-toluidina pura. A presença de anilina e de outras toluidinas como impurezas terá sido uma situação de todo provável. As impurezas presentes terão tido papel determinante no preparado obtido; o próprio aspecto de sujidade que apresentava e que determinou a sua purificação com etanol são disso indício. A sagacidade da preparação não pode ser pois creditada à preparação reactiva em si mesma, mas sim à confiança depositada na preparação feita, confiando que o produto obtido, não obstante o aspecto que apresentava, merecia ser tido em consideração e analisado com o necessário interesse.

A estrutura molecular adoptada pelo referido Índice de Cores foi também a adoptada por G. Schultz nas últimas edições do seu Farbstofftabellen de G. Schultz [19], e acabou por ser a adoptada pelo Chemical Abstracts.

Pese embora a autoridade de todas estas instituições químicas que deram o seu aval à estrutura molecular identificada como a estrutura molecular da mauveína- $B$, nuns casos, e como a
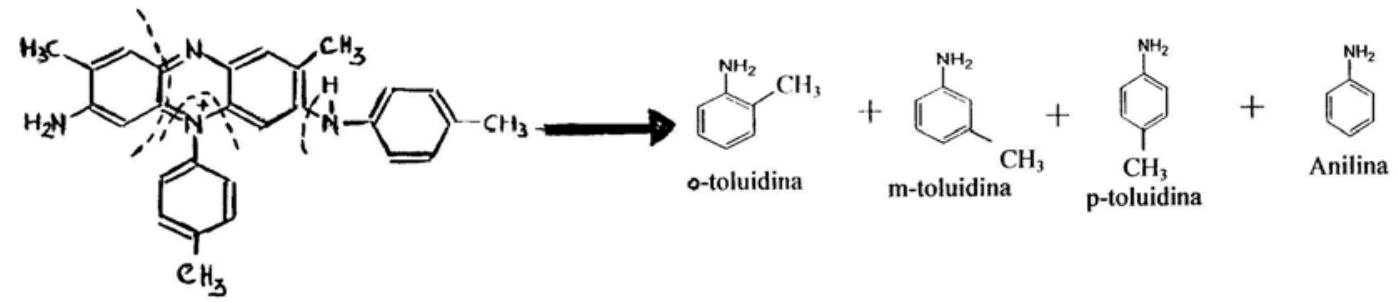
mauveína-A, noutros, a questão não estava encerrada. Já na década de 1990, Otto Meth-Cohn, Professor de química orgânica do Departamento de Química da Universidade de Sunderland, ao estudar o corante em causa, concluía que a estrutura proposta não podia corresponder ao composto preparado por Perkin em 1856. Ela exigia que na preparação interviessem uma molécula de anilina e uma de cada um dos três isómeros, orto-, meta- e para- toluidina, um cenário nada realista, a seu ver, pois que o estudo do rendimento da reacção mostra que a $m$-toluidina não se produz em quantidade suficiente que permita a estrutura proposta. Levantada a dúvida, num contacto com a Empresa farmacêutica Zéneca Specialities que se reclama sucessora das preparações de Perkin, Otto Meth-Cohn conseguiu que o arquivista desta, Ken McGee, Ihe disponibilizasse uma garrafa com 120 anos, devidamente selada, contendo uma amostra devidamente autenticada da mauveína preparada na fábrica de Perkin, ao tempo das suas primeiras produções. Procedendo à sua análise química, juntamente com M. Smith, obteve resultados praticamente idênticos aos referidos pelo próprio Perkin. Por cromatografia, espectrometria de massa e ressonância magnética nuclear, concluiu que os componentes básicos do corante eram a $o$ - e a $p$-toluidina e a anilina, tal como o referira Kobenzel, em 1925. Com os resultados obtidos nestas análises, e tomando como referência a estrutura proposta por Kobenzel, que durante anos a comunidade científica passara a aceitar sem contestação, e que figurava, em particular, no acima citado Índice de Cores, os autores defenderam que a mauveína preparada por Perkin terá sido, de facto, uma mistura de dois acetatos de fenazina, o acetato de 3-amino-2-metil-5-fenil-7 ( $p$-tolilo) fenazina (mauveína-A) com o acetato de 3-amino-2,9-dimetil-5-fenil-7-( $p$-tolilo) fenazina, (mauveína-B), isto é, na posição 7 do ião fenazino ter-se-ia um grupo aminotoluilo e não um grupo aminofenilo; na posição 5 um grupo fenilo e não um grupo toluilo; e o grupo metilo estaria na posição nove e não na posição oito [20].

Também no Museu da Ciência de Londres existem, ainda hoje, várias amostras de diversos corantes cuja preparação é atribuída a Perkin. Entre elas figura uma amostra de acetato de mauveína. Peter Morris, curador principal do Museu para a área da química, defende tratar-se de uma amostra posterior a 1862, pelo que não poderá ser um dos spécimens mais representativos da mauveína produzida por Perkin em grandes quantidades, nos primeiros anos depois da sua descoberta [21]. Porém, o interesse na sua análise química, como a análise química de outras amostras de mauveína da mesma época existentes noutros Museus, continua a suscitar a curiosidade de vários estudiosos que não consideram assim que as análises de Otto Meth-Cohn e M. Smith tenham posto um ponto final na decifração do "mistério" da estrutura química da mauveína que foi sendo preparada por Perkin. Ninguém ficará muito surpreendido se em tempos próximos o assunto for retomado.
O "mistério da mauveína " preparada por Perkin está longe de se ter tornado algum dia numa polémica científica. Mas o simples facto de, em votação efectuada por um elevado número de químicos e historiadores da química, a sua síntese ter sido considerada como a quinta mais bela preparação experimental [22], mantém-no na ordem do dia, em particular na celebração de alguns factos e datas com algum significado histórico. Há dúvidas e questões que não foram ainda definitiva e totalmente desvanecidas... A mauveína preparada pelo método de Perkin perdeu o seu valor industrial e comercial; outros métodos de preparação foram surgindo e são hoje utilizados [23]. Como acima referimos, o corante em si já não tem hoje, praticamente, valor comercial. Porém, pelo facto de se tratar do primeiro grande corante preparado artificialmente que acabou por revolucionar a indústria deste tipo de substâncias, não surpreende que continue a despertar o interesse científico, a muitos e diversos níveis, como não surpreende que tenha sido a molécula com que o "site" de divulgação química "a molécula-domês" iniciou a sua página, em Dezembro de 1995 [24].

\footnotetext{
1 Nota do Editor: Embora não tenha sido encontrado, nos Dicionários de Língua Portuguesa, o termo "malveína" que, atendendo à relação com "flor de malva" seria, porventura, a designação mais adequada, foi mantida, nesta contribuição, a designação usada pelo autor, "mauveína", cuja utilização é justificada no texto.
}

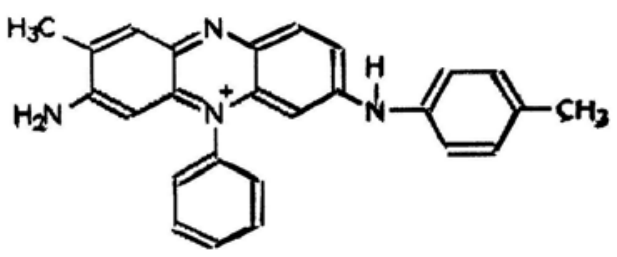

Mauveina -A



Mauveina-B 


\section{Referências}

[1] a) J.C.A.Pelletier, E.Caventou, Ann. Chim. XV(1820) 289; b) J.C.A.Pelletier, J. de Pharmacie IX (1823) 479.

[2] Não podemos deixar de referir aqui os trabalhos de Bernardino António Gomes sobre o princípio febrífugo de muitas quinas. Na sequência dos resultados da análise química que por incumbência da Real Academia de Sciencias de Lisboa, fizera, em colaboração com José Bonifácio Andrada e Silva, J.Croft e S. F.Mendo Trigoso de várias quinas provenientes do Rio de Janeiro, resultados esses apresentados na Academia a 18 de Julho de 1811, ainda que só publicados por esta em 1814 (in Memórias da Acad. Real das Sciencias de Lisboa, Tom.III, Pt.II, 1814, pp.96-118), Bernardino António Gomes, em artigo publicado no mesmo ano no Edinburgh Meddical and Surgical Journal (vol.7, 1811, pp.420431) afirmava ter isolado o cinchonino, que seria, em sua opinião, o princípio activo responsável pela cura das febres da malária. Nada avançou, porém, relativamente à sua composição química ou à sua estrutura molecular. Uma longa disputa científica com o médico José Feliciano de Castilho, Director do Jornal de Coimbra, que se prolongou por mais de oito anos, deixaria o seu trabalho fora das atenções da comunidade científica internacional, com o seu autor manifestamente agastado e cansado para aprofundar e reivindicar a originalidade e impacto da sua descoberta científica (vid. A.M. Amorim da Costa, Chemistry and the Scientific development of the
Country - The XIXth Century in Portugal in The Making of Chemistry - The Social History of Chemistry in Europe 1789-1914, Ed. D. Knight \& H. Kragh, Cambridge, Cambridge University Press, 1998, pp.278-287).

[3] S. Garfiel, Mauve: how one man invented a color that changed the world, Faber\& Faber, Londres, 2001.

[4] Otto Meth-Cohn, Anthony S. Travis, Chemistry in Britain 31 (1995) 547-549.

[5] Victor M.S. Gil, A. Amorim da Costa, M. Helena Caldeira, "33 Casos de Acaso em Ciência", Publ Gradiva, Lisboa, 1996.

[6] J. Jacques, L'Imprévu ou La Science des Objects Trouvés, Editions Odile Jacob, Paris, 1990

[7] W. I.B. Beveridge, Sementes da Descoberta Científica, EDUSP, S. Paulo,1981, p.20

[8] J. Jacques, o.cit., cp.V ; Royston M. Roberts, Serendipity, John Wiley \& Sons, N.Y. 1989; A.M. Amorim da Costa, Introdução à História e Filosofia das Ciências, Publ. Europa-América, Lisboa, 1986, pp.211-212.

[9] J. Campos, Serendipidade e Sistemas de Informação, Universidade de Coimbra, Departamento de Engenharia Informática, 2002.

[10] A. Dias de Figueiredo, José Campos, The serendipity equations, ICCBR 2001, Washington DC, Naval Research Lab, pp.121-124.

[11] José Campos, A. Dias Figueiredo, Proc. AAAl Fall Symposium on Chance Discovery, Massachussets, USA, 2002, pp. 48-60
[12] J. Campos, A.D. Figueiredo, ICCBR 2001, Washington DC, Naval Research Lab, pp.1-3.

[13] W.H.Perkin, J. Chem. Soc. 29 (1896) 1442.

[14] O. Fischer, E.Hepp, Chem. Ber. 26 (1893) 1194

[15] R. Nietzki, Chem. Ber. 29 (1896) 1442.

[16] G. Schultz, P.Julius, Tabellarische Übersicht der Künstlichen Organischen Farbstoffe, R. Gaertner's Verlg, Berlim, 1888.

[17] The Colour Index, Bradford, 1924, Ed. Society of Dyers and Colourists, entrada 846.

[18] A. Kobenzel, Oesterr. Chem. Ztg 28 (1925)25.

[19] G. Schultz, Farbstofftabellen, Leipzig, Akademische Verlagsgesellschaft, MBH, 1970.

[20] Otto Meth-Cohn, M. Smith, J.Chem. Soc., Perkin Trans.I (1994)5-7.

[21] P.Morris, History and Technology 22 (2006) 119-130.

[22] Chemistry at its most beautiful, http:// pubs.acs.org/jopurnals/cen/81.

[23] R. L. Scaccia, D. Coughlin, D. W. Ball, J. Chem Educ. 75(1998) 769-770.

[24] H.S.Rzepa, Elemental and Molecular Heritage in Internet-based display; idem, http://www. ch.ic.ac.uk /motm/ perkin/html.

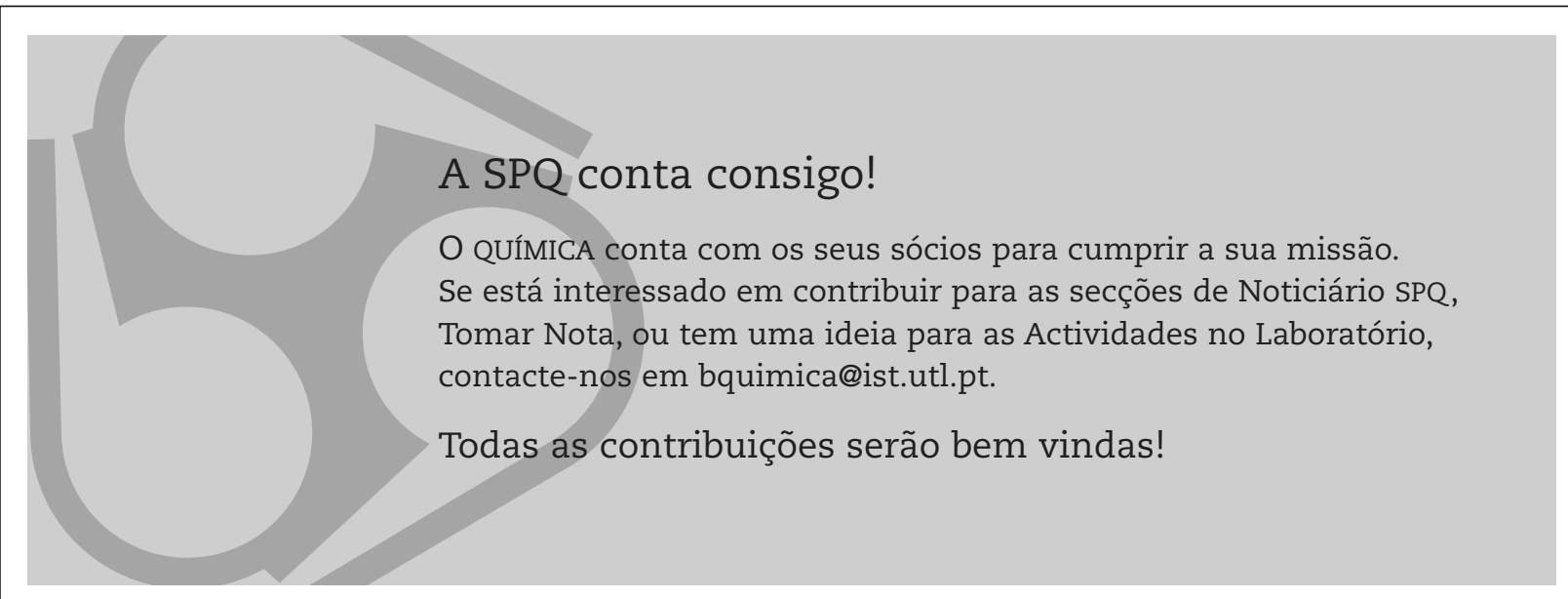

